\title{
Transferring flu protection
}

\section{By Tracey Baas, Senior Editor}

Two independent teams have shown proof of concept that gene transfer could be used to establish broad protection against influenza A viruses. ${ }^{1,2}$ Both laboratories are working to move their influenza A virus hemagglutinin-expressing vectors into humans for immunogenicity and safety testing.

Despite the availability of flu vaccines, the morbidity and mortality associated with influenza A-triggered seasonal and pandemic flu outbreaks are still high. Multiple groups have identified broadly neutralizing antibodies that target a range of influenza virus types and immunotherapies based on such antibodies that could be used as prophylactics or as treatments for already infected patients. ${ }^{3,4}$

Two teams have now engineered recombinant adeno-associated viruses (AAVs) expressing broadly neutralizing antibodies targeting influenza A.

\section{"Nasal delivery allows} the gene to be expressed locally in the nasal epithelia and not in other tissue. The vector does not integrate, and the nasal epithelial cells turn over naturally. Our goal is to provide a vector that protects for an influenza season with the option of readministration."

- James Wilson, University of Pennsylvania
These vectors could be used to transfer the capability to produce such antibodies to humans.

A team led by James Wilson developed an intranasal formulation of recombinant AAV serotype 2/9 expressing FI6, which is an antibody previously shown to protect mice against $\mathrm{H} 1, \mathrm{H} 3$ and $\mathrm{H} 5$ viruses. $^{5}$

Wilson is professor of pathology and laboratory medicine at the University of Pennsylvania and scientific founder of ReGenX Biosciences LLC, which develops recombinant $\mathrm{AAV}$ vectors for gene delivery.

FI6 is being developed by Humabs BioMed S.A., which has licensed the product to an undisclosed pharma.

Meanwhile, a group led by David Baltimore, professor of biology and president emeritus of the California Institute of Technology, has used AAV2/8 to direct muscle to produce stable levels of F10, a broadly neutralizing human $\mathrm{mAb}$ known to protect mice against $\mathrm{H} 1$ and $\mathrm{H} 5$ viruses. $^{6}$

\section{Breathing deep}

The Wilson team showed that mice receiving prophylactic nasal doses of AAV2/9 expressing FI6 survived a lethal influenza challenge three, four or seven days later. Mice pretreated one day before lethal challenge did not survive, although the symptoms of infection were delayed.

These results suggest the method provides relatively rapid onset of protection and would be useful for prophylaxis during pandemic outbreaks, or it could provide additional time to start therapeutic interventions.

In ferrets, nasal immunization with the FI6-expressing vector decreased virus replication and increased survival compared with administration of empty vector after lethal challenge with pandemic $\mathrm{H} 1$ or H5 influenza virus.

Macaques given an intranasal dose of AAV2/9 with a reporter gene expressed the gene product for more than 100 days. Peak vector expression was greater than that needed to protect ferrets from influenza challenge.

"The transient expression of the gene provides another layer of safety," said Wilson. "Nasal delivery allows the gene to be expressed locally in the nasal epithelia and not in other tissue. The vector does not integrate, and the nasal epithelial cells turn over naturally. Our goal is to provide a vector that protects for an influenza season with the option of re-administration."

Wilson said he is in discussions with an undisclosed funding agency to move the vector into humans.

He previously led a team that developed an AAV2/8 vector that replicates in epithelial cells in the lung and could be used to treat cystic fibrosis and $\alpha_{1}$-antitrypsin (AAT; A AT; SERPINA1) deficiency. ${ }^{7}$

\section{Muscle for hire}

The Baltimore group showed that mice intramuscularly injected with AAV2/8 encoding F10 were protected from lethal challenge with either of three different influenza H1 strains. Protection lasted for at least 11 months after gene transfer.

The vector also protected aged or immunocompromised mice from lethal influenza infection. These findings suggest the strategy might be useful to protect the elderly-a population in which the majority of deaths occur from seasonal influenza.

However, in ferrets immunized with the same vector, antibody production was 100 -fold less than that seen in mice and did not protect ferrets from influenza challenge.

The researchers hypothesized that the expression difference could be because of the human antibody's decreased half-life in ferrets compared with in mice.

Baltimore said he was not concerned about the ferret data. "The antibodies are human, and so we are predicting they will have the greatest half-life and immunogenicity in human sera," he told SciBX. "Our ultimate goal for AAV vectors, whether targeting influenza or HIV, is lifelong protection. The primary focus of my team right now is targeting HIV. Influenza is a secondary goal."

Baltimore has previously used AAV2/8 to direct muscle to produce stable levels of broadly neutralizing anti-HIV mAbs. The mAbs resulted in protection against HIV in humanized mice, in which they persisted for over a year. ${ }^{8}$ The team is now manufacturing a clinical product and plans to start clinical trials in the next year or two in collaboration with the Vaccine Research Center at the NIH. 


\section{Positioning the vector}

For both gene transfer approaches, showing adequate expression and safety in the clinic should be the next step, according to Gary Nabel, SVP and CSO of Sanofi.

"Safety will be a significant issue since long-term expression is intended, and it would be advisable to have a mechanism to terminate gene expression in the event that adverse events are encountered," he told SciBX. "It will also be important to determine whether immune responses to either the antibody or to the vector are observed in significant numbers of subjects."

"The biggest challenge will be proving the safety of the approach," agreed Philip Johnson, CSO and EVP director of The Children's Hospital of Philadelphia Research Institute. "Because there are existing efficacious vaccines, this approach for influenza might meet more resistance than, say, for HIV, malaria, tuberculosis or hepatitis C, 'for which no vaccines exist.

Johnson's lab has used an AAV2/8 vector to produce broadly neutralizing anti-HIV $m A b s$ in nonhuman primates. The $\mathrm{mAbs}$ protected against simian immunodeficiency virus (SIV) and persisted for up to one year. ${ }^{9}$

Adolfo García-Sastre, professor of microbiology and co-director of the Emerging Pathogens Institute at the Icahn School of Medicine at Mount Sinai, thinks the most logical population for the new flu vaccine approaches is elderly or immune-compromised individuals. "The most obvious advantage of the method is the ability to protect individuals at risk of severe disease for which traditional vaccine efficacy is low," he said.

Nabel agreed. "Commercial flu vaccines are much less effective in elderly individuals because they generate less robust immune responses," he said. "The elderly suffer much higher mortality and may have greater exposure in hospital and chronic care settings. The risk-benefit ratio of such an approach is therefore more favorable in this group."

García-Sastre did say that relying on only one antibody to provide universal protection might be overly optimistic.

"Although some influenza cross-reactive antibodies have been described that neutralize $\mathrm{H} 1, \mathrm{H} 3$ and influenza $\mathrm{B}$ viruses, these antibodies neutralize only a few specific virus strains," he said.
Both the Baltimore and Wilson teams plan to test their vectors in humans to determine safety and immunogenicity. The teams have filed for patents covering their respective findings, and the IP is available for licensing.

Baas, T. SciBX 6(24); doi:10.1038/scibx.2013.591

Published online June 20, 2013

\section{REFERENCES}

1. Limberis, M.P. et al. Sci. Transl. Med.; published online May 29, 2013; doi:10.1126/scitranslmed.3006299

Contact: Maria P. Limberis, University of Pennsylvania, Philadelphia, $\mathrm{Pa}$.

e-mail: limberis@mail.med.upenn.edu

Contact: James M. Wilson, same affiliation as above e-mail: wilsonjm@mail.med.upenn.edu

2. Balazs, A.B. et al. Nat. Biotechnol.; published online June 2, 2013; doi:10.1038/nbt.2618

Contact: David Baltimore, California Institute of Technology, Pasadena, Calif. e-mail: baltimo@caltech.edu

3. Dreyfus, C. et al. Science 337, 1343-1348 (2012)

4. Baas, T. SciBX 5(33); doi:10.1038/scibx.2012.859

5. Corti, D. et al. Science 333, 850-856 (2011)

6. Sui, J. et al. Nat. Struct. Mol. Biol. 16, 265-273 (2009)

7. Limberis, M.P. \& Wilson, J.M. Proc. Natl. Acad. Sci. USA 103, 12993-12998 (2006)

8. Balazs, A.B. et al. Nature 481, 81-84 (2011)

9. Johnson, P.R. et al. Nat. Med. 15, 901-906 (2009)

\section{COMPANIES AND INSTITUTIONS MENTIONED}

California Institute of Technology, Pasadena, Calif. The Children's Hospital of Philadelphia Research Institute, Philadelphia, $\mathrm{Pa}$.

Humabs BioMed S.A., Bellizona, Switzerland Icahn School of Medicine at Mount Sinai, New York, N.Y. National Institutes of Health, Bethesda, Md.

ReGenX Biosciences LLC, Washington, D.C. Sanofi (Euronext:SAN; NYSE:SNY), Paris, France University of Pennsylvania, Philadelphia, $\mathrm{Pa}$. 